\section{Access to primary dental care for cleft lip and palate patients in South Wales}

\author{
S. K. Bhatia ${ }^{1}$ and M. M. Collard ${ }^{2}$
}

VERIFIABLE CPD PAPER

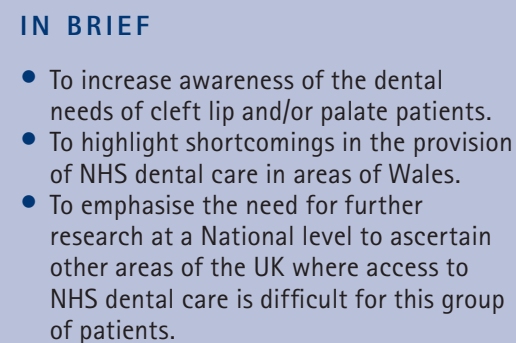

Aim To determine the provision of NHS primary dental care for children with cleft lip and/or palate in South Wales and the ease of accessing this dental care. Method A postal questionnaire was sent to all cleft lip and/or palate patients under the age of $18(n=750)$ in South Wales. The questionnaire identified patients' medical history, episodes of dental emergency, distance from home to dental surgery and ease of accessing primary dental care. To increase the response rate a second questionnaire was posted to non-responders. Results The response rate was 49\% (368/750). The majority of patients $(92 \%, n=340)$ attended a dentist. Over $17 \%(n=61)$ had suffered an episode of dental emergency. About $63 \%$ $(n=240)$ lived within 5 miles of their primary dental care provider, and 13\% $(n=66)$ lived more than 10 miles away. Other medical problems were found in over 30\% $(n=111)$ of the sample. Parents of 39\% $(n=107)$ found it difficult or impossible to access a local NHS dentist. Conclusion Many children with cleft lip and/or palate find it difficult or impossible to access NHS primary dental care. Shortcomings in the services provided to this high risk group have been highlighted. Further research is needed at national levels to evaluate the extent of the shortcomings and propose methods to overcome them.

\section{INTRODUCTION}

Cleft lip and/or palate (CL/P) are among the most common congenital abnormalities, affecting 1 in 700 live births in the UK. ${ }^{1}$

Children with CL/P may have complex dental problems and a number will require multidisciplinary care during their childhood and adolescence. ${ }^{1}$ Associated dental defects can include: incisor displacement, presence of supernumerary teeth, hypodontia, enamel hypoplasia, microdontia and unusual shaped teeth, transposition and geminated/fused teeth. ${ }^{2}$ Evidence has shown that this group of patients are at a higher risk of developing dental caries compared with the general population ${ }^{3}$ (Fig. 1). Young children with a cleft lip and/or palate are reported to experience more dental fear compared with children

${ }^{*}$ Specialist Registrar in Paediatric Dentistry, University Dental Hospital, Cardiff, CF14 4EA; ${ }^{2}$ Consultant in Paediatric Dentistry, South Wales Cleft Team, Morriston Hospital, ABMU Trust, Swansea, SA6 6NL

*Correspondence to: Ms Shannu K. Bhatia Email:BhatiaSK@cardiff.ac.uk

\section{Online article number E10}

Refereed Paper - accepted 21 December 2011

DOI: 10.1038/sj.bdj.2012.186

${ }^{\circledR}$ British Dental Journal 2012; 212: E10 in a normative control group, further complicating their dental care. ${ }^{4}$

About 21\%-37\% of children with CL/P are reported to have other non-associated medical problems. In addition these children often have to deal with psychological and social issues. ${ }^{1}$

Children with $\mathrm{CL} / \mathrm{P}$ require coordinated care from a range of clinical specialists over many years. In 1998 the Clinical Standards Advisory Group (CSAG) investigated the need for commissioning of specialist services in the UK for cleft patients. ${ }^{5}$ Following their recommendations, cleft care has evolved into a multidisciplinary approach with 14 cleft centres across the UK. The 1998 CSAG report also recommended that dental services be provided for these patients throughout childhood and adolescence. ${ }^{5}$ Dental care should ideally be provided by specialists in paediatric dentistry in collaboration with the patient's own general dental practitioner who can provide routine dental treatment and preventive advice for these patients.

In South Wales more than 40 children are born with $\mathrm{CL} / \mathrm{P}$ every year. A dedicated multidisciplinary cleft team is required to provide care for these patients. It has become

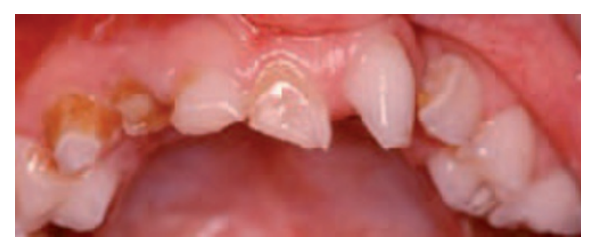

Fig. 1 Children with cleft lip and/or palate are reported to have a higher incidence of dental caries

apparent that patients living in South Wales are finding access to NHS primary dental care difficult. The aim of our study was to determine the provision and ease of access to NHS primary dental care for cleft lip and palate patients in South Wales.

\section{METHOD}

The study was a questionnaire-based audit carried out in 2009. The questionnaire was initially pilot tested on a sample of 30 patients, following which a minor modification was made to improve the clarity of one of the questions. The South Wales cleft team was consulted before conducting this study and approval gained from the clinical director of the cleft team.

The questionnaire together with a covering letter explaining the purpose of the study and a prepaid return envelope were sent to the parents/guardians 
of all patients under the age of 18 years ( $n=750$ ) whose details were held on the cleft database in the Cleft Unit at Morriston Hospital, Swansea.

A second questionnaire was posted to non-responders if no reply was received after one month. The questionnaire identified the patient's dental attendance, distance and ease of access to NHS primary dental care, other medical conditions, episodes of dental emergency and provision of preventive dental advice (Fig. 2). Space was provided on the questionnaire form for any additional comments to be recorded.

The patient's addresses were plotted on a map of Wales according to their postcodes (Fig. 3).

\section{RESULTS}

A total of 368 received responses were analysed; a response rate of 49\%.

The majority of patients $(92 \%, n=340)$ reported to regularly attend a dentist. The majority of these patients $(52 \% ; n=191)$ were seen by an NHS general dental practitioner, and a further 15.5\% ( $\mathrm{n}=57)$ reported to visit other types of dentist including community dentists and/or private practitioners. There was no response to this question by $6 \%(n=24)$ of parents. Of the children regularly attending a dentist, $61 \%(n=223)$ reported to receive checkups at six monthly intervals and 9\% ( $\mathrm{n}=34$ ) more frequently. A further $21 \%$ $(\mathrm{n}=76)$ were seen at 6-12 monthly intervals and the remainder of the sample were seen at intervals greater than 12 months, infrequently seen or not seen at all (Fig. 4). Preventive advice was received by a majority (86\%, $\mathrm{n}=317$ ) of the patients.

When asked as to why the children were not regularly seen by a dentist, 63\% $(\mathrm{n}=17)$ responded that they were unable to find an NHS dentist, while 15\% ( $=4)$ reported that their dentist was not able to provide treatment due to their child having a cleft. Around 22\% ( $n=6)$ gave other reasons including dental anxiety (Fig. 5).

Parents of 22\% ( $n=82$ ) of the patients found it difficult and 7\% $(n=25)$ impossible to access an NHS dentist (30\% of whom had significant medical problems). The question was left blank in $11 \%(n=42)$ of the questionnaires (Fig. 6).

Although a majority of the children $(63 \%, n=32)$ lived within 5 miles of their primary dental care provider, nearly 50

\begin{tabular}{|c|c|}
\hline Audit of Dental Access for Cleft Patients & Elliott label \\
\hline Please circle appropritate response & \\
\hline $\begin{array}{l}\text { 1. Does your child regularly attend a dentist? } \\
\text { If no go to question } 5\end{array}$ & Yes/No \\
\hline 2. If yes, is this dentist a: & $\begin{array}{l}\text { High street dentist NHS/Private } \\
\text { Community/School/Clinic dentist } \\
\text { Hospital dentist }\end{array}$ \\
\hline 3. Distance to dentist from your home: & $\begin{array}{l}\text { Less than } 5 \text { miles } \\
5 \text { - } 10 \text { miles } \\
\text { Greater than } 10 \text { miles }\end{array}$ \\
\hline 4. How often does your child see this dentist: & $\begin{array}{l}\text { Every } 6 \text { months } \\
\text { Every } 6-12 \text { months } \\
\text { Occasionally } \\
\text { Hasn't been seen for more than a year } \\
\text { Not sure when they were last seen }\end{array}$ \\
\hline 5. If your child does not see a dentist regularly, why not? & $\begin{array}{l}\text { Unable to find an NHS dentist } \\
\text { Dentist doesn't want to treat due to cleft } \\
\text { Other reason (please give a reason) }\end{array}$ \\
\hline 6. Have you found accessing an NHS dentist: & $\begin{array}{l}\text { Easy } \\
\text { Difficult } \\
\text { Impossible }\end{array}$ \\
\hline $\begin{array}{l}\text { 7. Have you received any dental advice about diet } \\
\text { or tooth cleaning? } \\
\text { If yes, who from? }\end{array}$ & $\begin{array}{l}\text { Yes/No } \\
\text { Own dentist } \\
\text { School dentist } \\
\text { Cleft dentist/dental therapist } \\
\text { Cleft nurses } \\
\text { Other }\end{array}$ \\
\hline 8. Have you had to take your child to a dentist as an emergency? & Yes/No \\
\hline 9. If yes, was it: & $\begin{array}{l}\text { Your usual dentist } \\
\text { Emergency dentist } \\
\text { Accident and emergency } \\
\text { Dental hospital } \\
\text { Other }\end{array}$ \\
\hline $\begin{array}{l}\text { 10. Does your child have any medical problems other than a cleft } \\
\text { If yes, what are their medical problems? }\end{array}$ & p and/or palate? \\
\hline Please feel free to write on the back of this sheet if there are any & omments you would like to make. \\
\hline
\end{tabular}

\section{Fig. 2 Questionnaire}

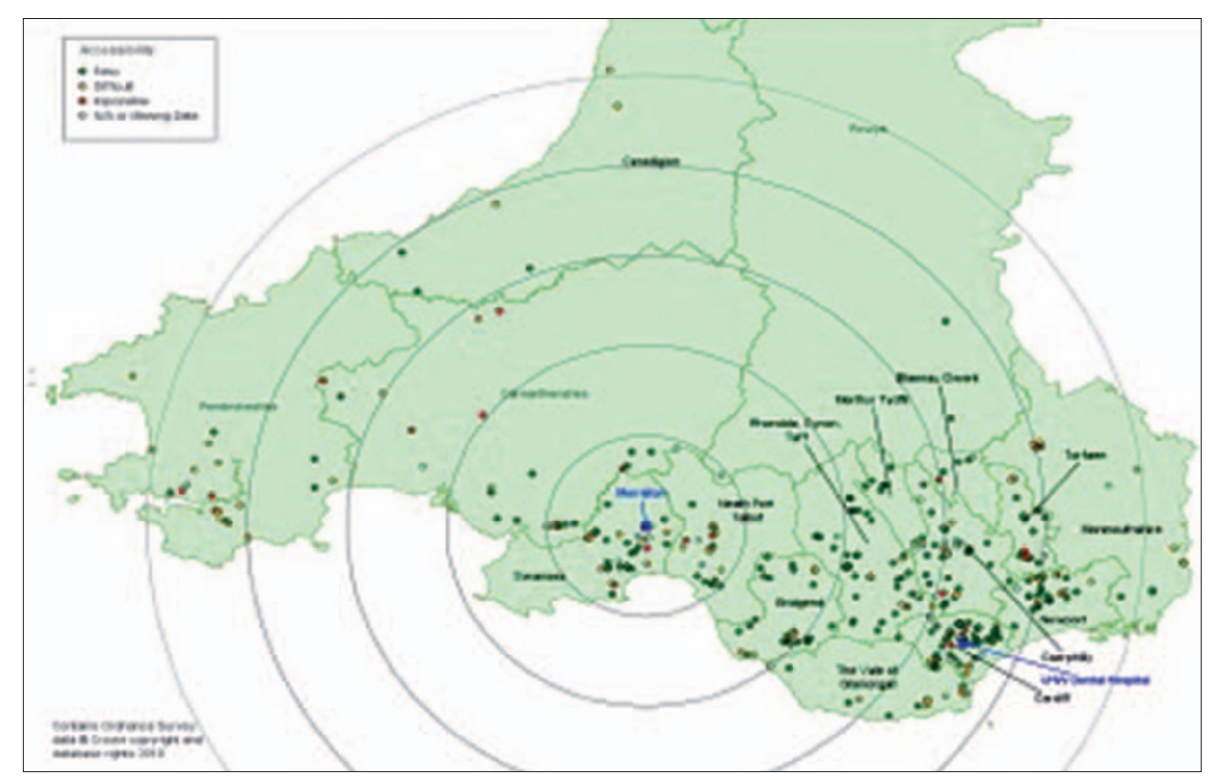

Fig. 3 The ease of accessing primary dental care. Green dots = easy, yellow dots = difficult, red dots = impossible. The cleft unit is based at Morriston Hospital, Swansea

children $(13 \%, \mathrm{n}=47)$ lived more than 10 miles away. Over 60 patients (16\%) had experienced an episode of dental emergency. The most common reasons being broken orthodontic appliances and dental infection and pain (Fig. 7).

Medical problems were found in 30\% ( $n=111)$ of the sample, the most commonly 


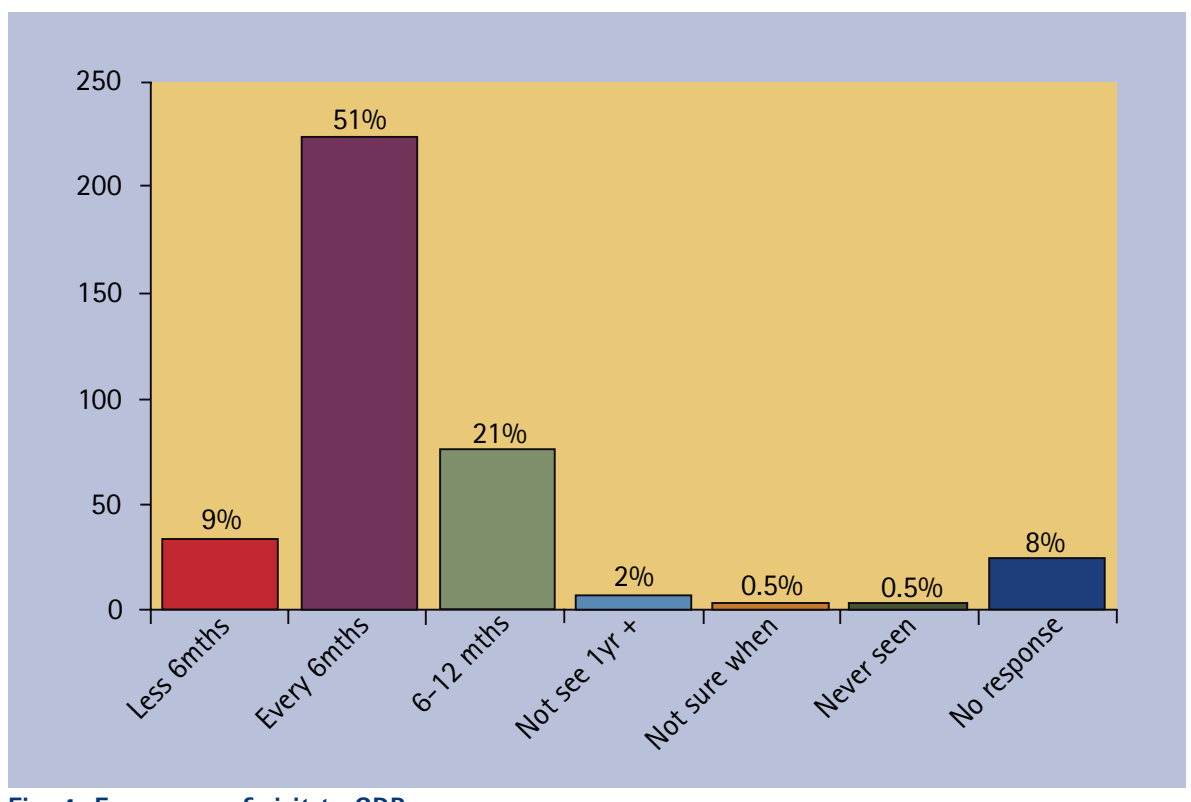

Fig. 4 Frequency of visit to GDP

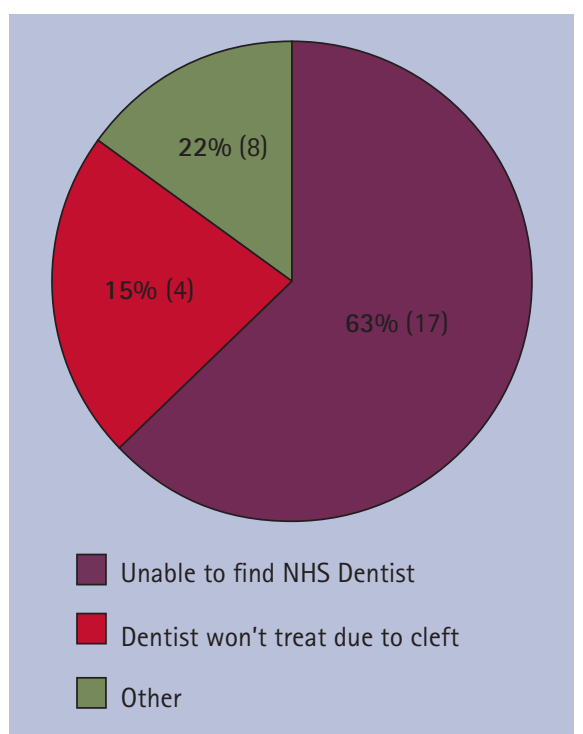

Fig. 5 Reason for not being seen regularly by a dentist

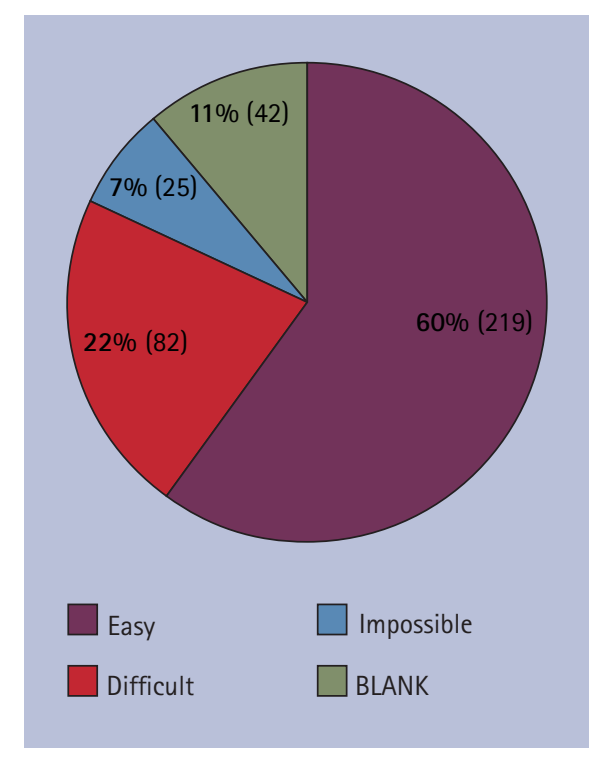

Fig. 6 Ease of accessing primary dental care reported conditions included asthma, ENT problems, craniofacial syndromes and cardiac problems.

\section{DISCUSSION}

Children with CL/P should be considered a high priority group by dentists due to their often complex medical and dental requirements. Dental pain or infection has a number of detrimental effects including interference with nutrition and loss of sleep, ${ }^{6}$ and is therefore unacceptable in any child. Early loss of teeth can give negative dental experiences to the child, and may complicate and prolong the orthodontic treatment of children with $\mathrm{CL} / \mathrm{P}{ }^{3}$ This survey sought to investigate the provision of NHS primary dental care for cleft lip and palate patients and ease of accessing this dental care.

Postal questionnaires are widely used to collect data in health research and are often the only financially viable option when collecting information from a large, geographically dispersed population, ${ }^{7}$ as in the cohort of patients in this study. However, postal questionnaires can have a low response rate. In order to maximise the validity of our study the non-responders had been posted a second questionnaire. Our study had a response rate of $49 \%$ with 368 responses. The low response rate was disappointing as it can create bias. The low response rate could be linked with the complex medical and social issues children with $\mathrm{CL} / \mathrm{P}$ often suffer, in addition to the multiple hospital appointments the families have to attend. A questionnairebased study carried out in 2000 targeting 4-8-year-olds with cleft lip and palate had a response rate of $77 \%$; however, the sample size was smaller with only 109 responses. $^{8}$

Dental health contributes to the overall health of the patient, therefore it is essential that all children with CL/P receive preventive dental advice and have convenient access to primary dental care. It was reassuring to note that the majority of patients $(92 \%, n=340)$ were able to access NHS dental care and reported receiving preventive advice, although this advice was not always received from their primary care provider but from members of the cleft team. Studies have shown that when compared to controls, children with cleft palate exhibit higher decayed/missing/filled teeth (DMFT) and DMFT scores, poorer oral hygiene, and longer oral clearance time. ${ }^{3}$ The DMFT scores of cleft children in Wales (2.68 in 2008) $)^{9}$ are reported to be higher than those in England and Scotland. Our study showed that regular (six monthly or less) dental checkups were carried out on $61 \%(n=223)$ of the children only. Long distances to travel to receive dental checkups could have contributed to this, with 47 children in our study living more than 10 miles away from the primary dental care provider. Indeed studies have shown transportation difficulties can lead to poor attendance. ${ }^{10}$ The large distances to travel to receive dental care is further evident in Figure 3, which shows the map of South Wales with patients plotted according to their postcodes. The distance to travel can also impact significantly when children have to receive emergency dental care. Twenty children (5\%) reported having travelled 5-10 miles or more to receive emergency dental care and this is a cause for concern.

Children with medical problems are at the risk of developing systemic complications from dental infections. Thirty percent $(n=111)$ of the children included in our study suffered from additional medical problems ranging from asthma to complex cardiac or craniofacial syndromes. This correlates with the report that $21 \%-37 \%$ of children with CL/P are reported to have other non-associated medical problems. ${ }^{1}$ Parents of $26 \%$ ( $n=29$ ) of children with additional 
medical problems reported finding it difficult or impossible to access NHS dental care and 20\% ( $n=22)$ had suffered an episode of dental emergency including pain and infection. The difficulty in accessing primary dental care is likely to have long term implications on their oral health and in turn general health.

Parents of 82 children reported to find it difficult or impossible to access NHS dental care. The map demonstrates that this problem is not only confined to the more rural areas of West Wales but parents living in city areas also reported difficulties finding a dentist prepared to treat them as NHS patients. Some parents reported that their dentists were not able to treat the children due to the cleft. This problem may be overcome by postgraduate training aimed to improve the knowledge and confidence of dental care providers in general practice and in community dental services. Indeed the lead paediatric dentist for the South Wales Cleft Team has begun to update local general dental practitioners, community dentists, DCPs and health educators regarding the dental management of cleft children. It is also important for the cleft team to maintain and develop links with local primary care providers so that they are clear as to what their role should be in the care of these children. Given the often complex medical and dental needs of these patients there is a case for increasing the strength of specialists in paediatric dentistry in Wales to provide improved access to specialist care in conjunction with good primary care for children with CL/P.

It has become apparent that patients living in South Wales are finding access to NHS dentists difficult as fewer dentists are accepting and treating NHS patients. The results of this study have raised concerns over the care provided to this vulnerable and high risk group of patients with

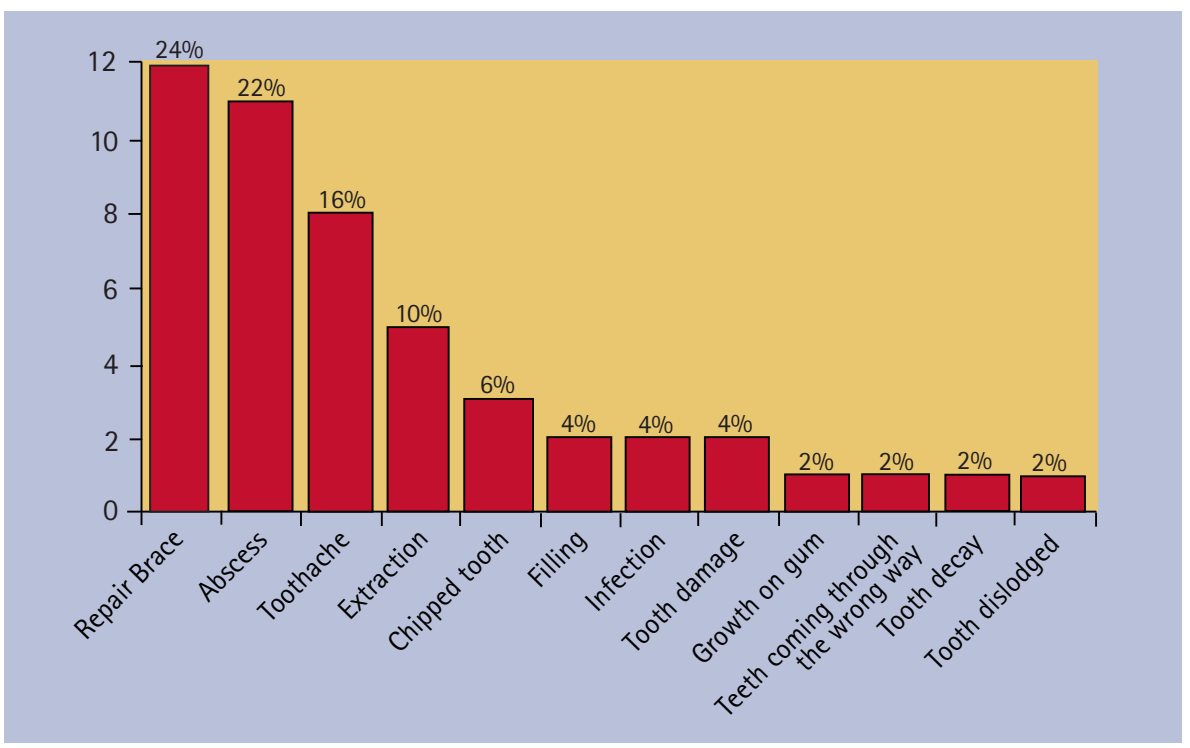

Fig. 7 Reason for dental emergency

many reporting that they find it difficult or impossible to access NHS primary dental care. This may lead to the financial strain of private dentistry on a low income family and/or poorer dental health as parents do not take their children to a dentist at all. Further research is needed at a national level to fully identify those areas within Wales where patients are not able to find NHS dental care.

\section{CONCLUSION}

Dentists should view children with cleft lip and/or palate as a high priority group due to their often complex medical problems and dental requirements. Access to local NHS dentists is of vital importance to help these patients maintain good dental health throughout childhood and adolescence. The results of this study have shown that a significant number of patients with CL/P find it difficult or impossible to access NHS primary dental care. Shortcomings in the services provided to this high risk group have been highlighted. Further research is needed at national level to evaluate the extent of these shortcomings and propose methods to overcome them.

1. Hodgkinson P D, Brown S, Duncan D et al. Management of children with cleft lip and palate: a review describing the application of multidisciplinary team working in the condition based upon the experiences of a regional cleft lip and palate centre in the United Kingdom. Fetal Matern Med Rev 2005; 16: 11-27.

2. Rivkin C J, Keith O, Crawford P J, Hathorn I S. Dental care for the patient with cleft lip and palate. Part 1: from birth to the mixed dentition stage. Br Dent J 2000; 188: 78-83.

3. Cheng $L L$, Moor S L, Ho C T. Predisposing factors to dental caries in children with cleft lip and palate: a review and strategies for early prevention. Cleft Palate Craniofac J 2007; 44: 67-72.

4. Vogels W E, Aartman I H, Veerkamp J S. Dental fear in children with a cleft lip and/or cleft palate. Cleft Palate Craniofac J 2011; 48: 736-740.

5. Clinical Standards Advisory Group. Report on cleft lip and/or palate. London: The Stationery Office: 1998

6. Fayle S A, Welbury R R, Roberts J F. British Society of Paediatric Dentistry: a policy on management of caries in the primary dentition. Int J Paed Dent 2001; 11: 153-157.

7. Edwards P, Roberts I, Clarke M et al. Increasing response rates to postal questionnaires: systematic review. Br Med J 2002; 324(7347): 1183.

8. McDonagh S, Pinson R, Shaw A J. Provision of general dental care for children with cleft lip and palate - parental attitudes and experiences. $\mathrm{Br}$ Dent J 2001; 189: 432-434.

9. M M Collard. South Wales Cleft team audit data 2008. Personal communication.

10. Richardson A. Failed appointments in an academic orthodontic clinic. Br Dent J 1998; 184: 612-615. 